\title{
Ataques à redução de danos em Recife: o consultório de rua
}

\author{
Attacks on harm reduction in Recife, Pernambuco: \\ the street clinic
}

Evelly Nathália Lira de Araújo*

\begin{abstract}
Resumo - O estudo objetiva compreender o significado e as contradições nas mudanças das ações do consultório de rua na Rede de Atenção Psicossocial da cidade do Recife, a partir de 2013, com base nos relatos de redutores(as) de danos. Trata-se, para fins gerais, de um estudo de caráter exploratório norteado pela teoria crítica marxista, que se utilizou da análise de entrevistas realizadas com agentes redutores de danos do Consultório de Rua de Recife para discutir os resultados apresentados. O desmonte dessas ações em Recife articula aspectos dos interesses econômicos, políticos e ideológicos. As entrevistas indicaram um processo silencioso e sutil de desarticulação das ações de redução de danos com a desconfiguração e descontinuidade do processo de trabalho, visto que as investidas das gestões para consolidar esse desmonte são multifacetas. Essa realidade dialoga com alianças políticas junto a empresários que lucram com o isolamento e internações de pessoas usuárias de drogas.
\end{abstract}

Palavras-chave: agente redutor(a) de danos; consultório de rua; política sobre drogas; redução de danos.

\begin{abstract}
The study aims to understand the meaning and contradictions in the changes in the actions of the Street Clinic in the Psychosocial Care Network in the city of Recife, Pernambuco, from 2013 on, based on the reports of harm reduction specialists. This is, for all purposes, an exploratory study guided by Marxist critical theory, which uses verification analysis with damage reduction specialists from Recife's Street Clinics to discuss the results presented. The dismantling of these initiatives in Recife articulates aspects of economic, political, and ideological interests. The interviews pointed to a silent and subtle process of dismantling harm reduction actions with the deconfiguration and discontinuity of the work process, as management efforts to consolidate this dismantling have multiple facets. This reality is a consequence of with political alliances made with businessmen who profit from the isolation and hospitalization of drug users.

Keywords: harm reduction specialist; street clinic; drug policy; harm reduction.
\end{abstract}

\footnotetext{
* Assistente Social - UFPE, especialista em Saúde Mental - UPE e mestranda no Programa de Pós-graduação em Serviço Social-UFPE. Redutora de Danos- Escola Livre de Redução de Danos. E-mail: evelly.araujo@ufpe.br. ORCID: https://orcid.org/0000-0002-8204-0369.
} 


\section{Introdução}

O cuidado à pessoa que faz uso de substâncias psicoativas na atualidade é marcado pela multiplicidade e complexidade de abordagens, e engendrado por disputas ideopolíticas e econômicas historicamente postas. Em Recife, a trajetória da estratégia de redução de danos (RD) foi e é referência no cenário nacional. Entretanto, as aproximações cotidianas com o consultório de rua e serviços substitutivos para álcool e outras drogas apontaram inquietações sobre o atual momento no campo público-estatal das ações de redução de danos. Por isso, o estudo - fruto do trabalho de conclusão da residência, do Programa de Residência Multiprofissional em Saúde Mental da Universidade de Pernambuco (UPE) - objetiva compreender o significado e as contradições nas mudanças das ações do consultório de rua na Rede de Atenção Psicossocial da cidade do Recife, a partir de 2013, com base nos relatos dos(as) agentes redutores(as) de danos (ARD).

Entende-se que a orientação da redução de danos (RD) na política sobre drogas é prerrogativa para sua prática em qualquer serviço, equipe ou profissional envolvido com esta política ao acolher pessoas que fazem uso de substâncias psicoativas. Isso esboça um campo vasto para a proposta de análise deste estudo, mesmo para o recorte da cidade do Recife, sua Rede de Atenção Psicossocial e seus serviços de atenção a usuários(as) de drogas. Desta maneira, a escolha por enfatizar as equipes de consultório de rua tem o intuito de dialogar diretamente com a realidade de profissionais direcionados para o fazer estratégico da RD: os(as) agentes redutores(as) de danos (ARD), que no cotidiano do processo de trabalho experienciam os ataques sofridos por uma estratégia de cuidado contra-hegemônica. Além disso, a preferência metodológica de compreender o objeto de estudo a partir da análise dos relatos profissionais também se justifica pelo reconhecimento e documentação dessas práticas no SUS, em tempos de severos retrocessos.

A realização da coleta de dados ${ }^{1}$ ocorreu durante o último trimestre de 2020 e se deu a partir de um questionário simples em entrevista semiestruturada, com vistas a compreender qual local vem sendo atribuído às ações dos(as) redutores(as) de danos de âmbito público-estatal da cidade do Recife. Na tentativa de priorizar as discussões fomentadas nas páginas seguintes, optou-se por apresentar pequenos trechos das entrevistas.

Para isso, os seguintes critérios de inclusão foram direcionados: um(a) ARD de cada uma das seis equipes de consultório de rua, que correspondem à cobertura dos oito distritos sanitários da cidade do Recife, um(a) ARD atuante na supervisão, leia-se, na função de gestão das equipe, e um/

\footnotetext{
${ }^{1}$ Esta pesquisa foi submetida ao Comitê de Ética da Hemope da UPE, sendo aprovada em 14 out. de 2020, com parecer de n 4.338.941. A carta de anuência foi solicitada à Secretaria de Saúde do município, sendo autorizado o contato com as equipes dos seis Caps-AD da cidade. As entrevistas foram realizadas virtualmente, em virtude da crise sanitária e social da Covid-19, resguardando sigilo sobre as identidades dos(as) participantes.
} 


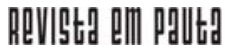

\} ATAQUES À REDUÇÃO - ARAÚJO, E. N. L. \}

DOI: $10.12957 /$ REP.2022.63527

a ARD da equipe de arte-educação do consultório de rua; todos(as) com tempo de atuação que varia de oito a 16 anos, podendo ter vínculos de trabalho por contrato profissional ou concurso público. Dessa forma, foram realizadas oito entrevistas, sendo três pessoas com vínculo por concurso público e cinco por contrato terceirizado via Santa Casa de Misericórdia ou Maria Lucinda.

\section{Drogas e redução de danos nos desarranjos da sociedade de classes}

A priori, sabe-se que, para trabalhar a problemática do consumo de drogas nas suas interfaces com a questão social, é necessário compreender o papel histórico das drogas no campo das necessidades humanas. Em uma perspectiva ontológica, Cristina Brites (2017) se apoia na filosofia da práxis lukácsiana para afirmar que as singularidades que perpassam o uso de psicoativos, compreendidas à luz das "escolhas e ações dos indivíduos sociais", assim são devido às possibilidades conduzidas pelas diversas modalidades da práxis social e seus sistemas de necessidades sociais, historicamente autoconstruídos e constituídos de conservações e superações, sendo este o constructo da totalidade social. Neste caso, o uso de drogas ao longo da história é produto da práxis.

Entretanto, a totalidade social no modo de produção capitalista se sustenta pelo acúmulo de riquezas, expressivamente mediado pela mercadoria e seu valor de troca (MARX, 2011). Por essa função acumuladora, as relações mercantis e monopolistas ao longo da história moderna reservam às drogas, além das indispensáveis atribuições culturais, ritualísticas e morais, o valor de troca centrado no acúmulo da mercadoria (CARNEIRO, 2018); nesse sentido, o "fetiche da mercadoria" atribui novas funções ao circuito de necessidades humanas impressos no "uso de drogas", que por essa via apresentam-se na forma do consumo (SOUZA, 2012).

Adiante, é no século XX que o consumo de drogas chega ao maior alcance mercantil. Em seus primeiros anos já se operavam tendências à ilicitude de algumas drogas, mas o circuito que se consolida em meados deste século reordena a produção, circulação e consumo de substâncias psicoativas a partir do lícito e ilícito em bases jurídico-morais, caracterizando o paradigma ideológico do proibicionismo (CARNEIRO, 2018). Esse paradigma projeta a chamada "guerra às drogas" como expressão tendenciosa de reatualização do conservadorismo, mais precisamente no pós-crise da década de 1970, quando os ideais conservadores são convocados para interferir na "reprodução social da barbárie" promovida pela ofensiva neoliberal, "reservando ao Estado a função coercitiva de reprimir violentamente todas as formas de contestação à ordem social e aos costumes tradicionais (BARROCO, 2015, p. 625). 


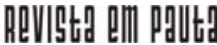

\} ATAQUES À REDUÇÃO - ARAÚJO, E. N. L. \}

DOI: $10.12957 /$ REP.2022.63527

Em meio à recusa neoliberal de enfrentar as expressões da questão social, afirma Wacquant (2001, p. 80), "a atrofia deliberada do Estado social corresponde a hipertrofia distópica do Estado penal", em que o atravessamento dos pressupostos de classe, raça e morais-cristãos posicionam a guerra às drogas como multiplicadora de dispositivos ultrarrepressivos (WACQUANT, 2001). Na realidade brasileira ${ }^{2}$, a guerra às drogas foi fortalecida pelas práticas ditatoriais, se firmando enquanto justificativa para intervir e reprimir a população pobre e preta, principalmente se considerado o processo de expansão das favelas brasileiras nas décadas de 1980 e 1990, quando o narcotráfico incide nas populações mais vulnerabilizadas de países periféricos como o Brasil.

Nessa composição, o paradigma da abstinência atua na produção de consensos acerca da questão das drogas como uma questão de saúde submetida à cura, e também se sustenta pelos pressupostos da psiquiatria e da moral cristã:

A moral cristã compõe, junto com a justiça e a psiquiatria, uma rede de instituições que tem por finalidade única e comum a abstinência. Porém, ao contrário da psiquiatria que se volta mais para a doença mental e da justiça que se volta mais para a delinquência, a moral religiosa inclui um terceiro elemento, a associação do prazer ao mal. (PASSOS; SOUZA, 2011, p. 158).

Por outro lado, a questão do uso de substâncias psicoativas no âmbito da saúde pública delineia tendências de debate protagonizadas por disputas dentro e fora do campo público-estatal, com avanços significativos nos últimos 35 anos. Os contrassensos dessas tendências se concentram, principalmente, na defesa de modelos de atenção à saúde de pessoas usuárias de drogas, necessariamente vinculada à defesa de projetos políticos, econômicos e societários.

Na realidade brasileira, essas tendências adentraram as disputas do campo da saúde pública, nas propostas de intervenção da política de saúde, a partir de medidas historicamente reivindicadas pelos movimentos sociais no processo de democratização brasileiro, através da reforma sanitária e psiquiátrica. Esses tensionamentos permitiram a construção de um novo modelo de atenção à saúde mental, que escoou em possibilidades de alinhamento ético, político e científico entre a atenção integral a usuários de álcool e outras drogas e a estratégia de redução de danos, no âmbito da política sobre drogas.

A RD é cercada por diversas concepções teóricas, que ora são compreendidas como política social, ora como abordagem, lógica, conceito

\footnotetext{
${ }^{2}$ Apesar de Wacquant ter analisado a política de encarceramento em massa dos EUA, a partir do governo de Ronald Reagan, há difusão sistemática em outros países, incluindo o Brasil. Entretanto, a história do Brasil é cercada pela criminalização e pelo punitivismo de raízes coloniais, escravocratas e ditatoriais, e pela vigilância do trabalho explorado e colonizado. Nesse sentido, o Estado brasileiro sempre foi categoricamente o Estado penal.
} 


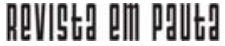

\} ATAQUES À REDUÇÃO - ARAÚJO, E. N. L. \}

DOI: $10.12957 /$ REP.2022.63527

ou estratégia (BRITES, 2006). Com ela, busca-se compreender as drogas como um atravessamento da realidade dos sujeitos que as consomem, mesmo que seu uso implique uma relação problemática. Parte do princípio da liberdade de escolha, pressupondo que nem todos(as) os(as) usuários(as) de substâncias psicoativas conseguem ou querem interromper o uso. Sua prática não precede fórmulas prontas com aplicação geral, mas ações voltadas para minimizar as consequências adversas do uso de drogas, consequências essas que perpassam prejuízos sociais, econômicos e/ou biológicos.

Enquanto a abstinência está articulada com uma proposta de remissão do sintoma e a cura do doente, a proposta de reduzir danos possui como direção a produção de saúde, considerada como produção de regras autônomas de cuidado de si. No caso da RD, a própria abstinência pode ser uma meta a ser alcançada, porém mesmo nesses casos trata-se de uma meta pactuada, e não de uma regra imposta por uma instituição. As regras da RD, mesmo a abstinência, são imanentes à própria experiência e não se exercem de forma coercitiva, enquanto regras transcendentais. (PASSOS; SOUZA, 2011, p. 160).

Nesse sentido, a oferta da RD, bem como o acesso a informações referentes, pode ser entendida aqui como um direito social e humano, uma estratégia democrática para qualificação do cuidado, implicada no desvelamento dos estereótipos criminalizantes e moralistas que acompanham o(a) usuário(a) nos espaços institucionais e comunitários, em busca da proteção de sua autonomia. Apesar disso, reconhecer a problemática do uso de substância como questão de saúde pública não implica, necessariamente, a validação cotidiana de práticas de redução de danos nos serviços de atenção à saúde da população usuária.

\section{A construção do cuidado à pessoa que consome drogas em Recife: o contexto público-estatal da redução de danos}

No Brasil, em 1989, a cidade de Santos foi pioneira nas tentativas de implementar um programa de troca de seringas na cidade portuária, considerando os altos índices de contaminação de usuários de drogas injetáveis por HIV/Aids. A partir da década de 1990, diversas propostas orientadas pela estratégia de RD foram se articulando em alguns estados do Brasil, em programas ou projetos que vez ou outra eram interrompidos por ações jurídico-legais (FONSECA, 2005).

E no social-liberalismo dos governos petistas que a redução de danos avança no âmbito da política sobre drogas, com a orientação de portarias, estruturação dos serviços e operacionalização da política de saúde mental, promovendo, progressivamente, a ampliação de práticas de RD no âmbito público-estatal. Considerado os avanços das discussões e mobili- 


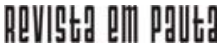

\} ATAQUES À REDUÇÃO - ARAÚJO, E. N. L. \}

DOI: $10.12957 /$ REP.2022.63527

zações em prol da temática e a possibilidade de participação social, o Ministério da Saúde (MS) institui a política de atenção integral a usuários de álcool e outras drogas no âmbito do Sistema Único de Saúde (SUS), ampliada pela Portaria n. 2.197, em 2004, na qual é proposta a orientação pela estratégia de redução de danos e a defesa de práticas intersetoriais de atenção integral, prevenção, promoção e assistência à saúde em Centros de Atenção Psicossocial para álcool e outras drogas (Caps-AD), nos termos da política de saúde mental - Lei n. 10.216/2001, marco da reforma psiquiátrica que engendrou o processo de desinstitucionalização.

Em 2005, o Ministério da Saúde regulamenta ações que visam à redução de danos, com a Portaria n. 1.028, e aponta a promoção da RD como diretriz da política nacional sobre drogas, ratificada em 2006 pelo Sistema Nacional de Políticas Públicas sobre Drogas (Sisnad). Apesar disso, o Sisnad, enquanto articulador dos diversos setores em torno da questão das drogas (SUS, Suas e judiciário), reuniu projetos antagônicos ao introduzir a redução de danos no âmbito da saúde e a manutenção da guerra às drogas no âmbito da justiça.

A Portaria $n^{\circ}$ 3.088/2011 (BRASIL, 2011) instituiu o cuidado em Redes de Atenção Psicossocial (Raps), descentralizado e integral a pessoas em sofrimento psíquico, decorrente ou não do uso de álcool e outras drogas, estabelecendo atribuições aos serviços de saúde nos diversos níveis e ampliando as estratégias de cuidado com a inclusão de serviços, como as Unidades de Acolhimento (UA). Essas unidades visam à garantia do cuidado continuado em tempo integral a pessoas com necessidades de proteção e acompanhamento terapêutico frente à vulnerabilidade social e acentuada necessidade decorrente do uso de substâncias. Apesar de sua importância para a ampliação e integração dos pontos de atenção à saúde na perspectiva territorial, a portaria insere as comunidades terapêuticas (CTs) como ponto de atenção da Raps, o que representou a possibilidade legal de encaminhar pessoas para espaços com recorrentes violações de direitos humanos e sociais. A este paradoxo cabe sinalizar que as CTs são incorporadas como serviços residenciais de caráter transitório, tal como as UAs, promovendo as relações público-privadas sob a oferta de serviços contrários aos princípios da RD e da reforma psiquiátrica.

Em Pernambuco e na cidade do Recife, os pioneiros no cuidado às pessoas com problemas decorrentes do uso de álcool e outras drogas foram o Centro Eulâmpio Cordeiro de Recuperação Humana e o Centro de Prevenção e Tratamento e Reabilitação de Alcoolismo (CPTRA), inaugurados em 1986 e 1990, respectivamente. Esses serviços se propunham a ofertar a assistência à saúde com base na multidisciplinaridade, ao desprender-se da lógica psiquiatrizante e hospitalocêntrica, buscando construir possibilidades no cuidado integral a pessoas usuárias de álcool, mas ainda regulados pelo princípio da abstinência, pela incipiência do debate (MELO, 2017). 


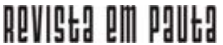

\} ATAQUES À REDUÇÃO - ARAÚJO, E. N. L. \}

DOI: $10.12957 /$ REP.2022.63527

Como registra a história, a efervescência do debate sobre a RD na cidade apontou caminhos frutíferos no campo científico e na construção de espaços de articulação. Em resposta aos debates locais e às articulações nacionais, as movimentações público-estatais em prol da RD se iniciam entre 2002 e 2003, com intervenções pontuais no período de carnaval, mas é em 2004 que a prefeitura lança o Programa + Vida, na gestão municipal de João Paulo (PT), como principal articulador da RD na cidade (RAMEH-DE-ALBUQUERQUE, 2017). Diferentemente da implementação nacional da estratégia, este programa concentrava eixos de atuação, com recurso, operacionalização e avaliabilidade; possuía uma coordenação municipal de redução de danos autônoma, ainda que vinculada às políticas de saúde mental e atenção básica, promovendo grandes realizações em prol do cuidado a partir da redução de danos.

Medeiros et al. (2010) destacam que o + Vida partia de três eixos de atuação: i) promoção, proteção e redução de danos; ii) assistência à saúde: tratamento e reabilitação; e iii) perspectiva epidemiológica. Na prática, isso se traduziu em ações de acesso a informações sobre RD, capacitações de profissionais que atuavam com a população usuária, efetivação de uma rede de assistência à saúde composta pelos Caps-AD, as casas do meio do caminho, chamadas também de albergues terapêuticos, mas que atualmente são as Unidades de Acolhimento (UA) e as unidades de desintoxicação, e, por fim, a validação do(a) profissional redutor(a) de danos para atuação direta no território (MEDEIROS et al., 2010; MELO, 2017):

Os redutores de danos eram pessoas identificadas na própria comunidade que passavam por capacitação e deveriam ser capazes de estabelecer uma relação respeitosa com a população consumidora de drogas nos espaços cotidianos, isto é, em ruas, bares, locais de lazer e esporte, entre outros, lugares onde se pudesse atuar para reduzir as vulnerabilidades vinculadas ao consumo de drogas. As ações individuais cotidianas visavam ao estímulo a comportamentos de proteção aos riscos associados ao consumo de drogas, vinculados à 'overdose', acidentes de trânsito, violências ou práticas sexuais inseguras'. Além das atividades de abordagem individual de rotina, os redutores de danos, também desenvolviam ações de redução de danos nos grandes eventos, conhecidas como +Vida no Forró, +Vida na Folia e +Vida no Trânsito. O +Vida no Trânsito chegou inclusive a ter reconhecimento internacional, ao receber, em 2004, o Prêmio Mundial da Saúde, do Ministério da Saúde e do Ministério das Cidades. (MELO, 2017, p. 128).

O cargo de agente redutor(a) de danos foi efetivado por Lei Municipal $n^{\circ} 17.400 / 2007$ pela prefeitura de Recife. O programa foi fortalecido com a abertura de mais de 70 vagas para o cargo de ARD por concurso público. Os(as) profissionais convocados neste concurso foram distribuídos entre as seis equipes que cobriam os seis Caps-AD da cidade e os então 


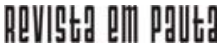

\} ATAQUES À REDUÇÃO - ARAÚJO, E. N. L. \}

DOI: $10.12957 /$ REP.2022.63527

albergues terapêuticos, ou UAs. Os dois anos seguintes marcaram também a contratação terceirizada de mais 40 ARDs, via Santa Casa de Misericórdia e Maria Lucinda, ambas organizações civis ou fundações que endossam as parcerias público-privadas no âmbito da saúde - problemáticas que ganharam força no estado com a gestão de Eduardo Campos (2007-2014), do Partido Socialista Brasileiro (PSB). Por outro lado, essas contratações abarcavam ARDs com trajetória na prática da redução de danos, em que muitos dos profissionais eram usuários ou ex-usuários de drogas.

Em 2011, Recife incorporou em suas equipes de redutores de danos a proposta do consultório de rua. Tratou-se da construção de dispositivos comunitários compostos por agentes redutores(as) de danos, com a oferta de cuidados em saúde aos usuários em seus próprios contextos de vida, a partir de práticas de RD nos territórios (PLENA et al., 2010). Nesse sentido, o consultório de rua vincula-se diretamente à política de saúde mental, álcool e outras drogas, no cuidado aos(às) usuários(as) de álcool e outras drogas, com base numa costura territorial da rede, mediando o acesso de usuários e usuárias ao Caps e à Raps. Para isso, o dispositivo conta com um automóvel para as ações nas ruas a fim de acessar, principalmente, as cenas de uso dos territórios e propor o cuidado à população de rua.

Dentro das possibilidades de construir caminhos para a redução de danos no município, o processo de implementação de ARDs na cidade provocou tensões no âmbito da saúde mental, mesmo porque as discussões relacionadas à redução de danos já eram questões conflituosas dentro da própria rede, em que muitos profissionais mantiveram a defesa do paradigma da abstinência (MORAES, 2005 apud MELO, 2017).

Além do + Vida, merecem destaque no cenário estadual a Ação Integrada de Atenção ao Crack e outras Drogas, e o Programa de Atenção Integral aos Usuários de Drogas e seus Familiares (Programa Atitude), ambos em 2011, respondendo ao cenário nacional "alarmista" de "pandemia do crack", ainda na gestão de Eduardo Campos (RAMEH-DE-ALBUQUERQUE et al., 2017). A valorativa contribuição do Programa Atitude está, principalmente, na junção da redução de danos à assistência social, sendo um dos principais espaços de reconhecimento da RD enquanto estratégia de cuidado até os dias atuais. O programa foi proposto como serviço de baixa exigência:

[...] com estratégias de prevenção e assistência e tem como principal objetivo garantir direitos às pessoas que usam drogas, principalmente o usuário de crack, a proteção social, desde cuidados primários, passando pela preservação da sua integridade física e pelo estímulo ao convívio socioafetivo. (WEST, 2016, p. 53).

Em 2012, o Ministério da Saúde substituiu a proposta do consultório de rua, que já contava com 92 equipes ao redor do país, para o consultório na rua. Este último não compunha ARDs nas equipes, mas profissionais de nível superior (assistentes sociais, psicólogos(as), terapeutas 


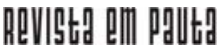

\} ATAQUES À REDUÇÃO - ARAÚJO, E. N. L. \}

DOI: $10.12957 /$ REP.2022.63527

ocupacionais, enfermeiros(as), dentistas etc.), além de poder contar com agentes sociais. As equipes do consultório na rua surgem ainda na Portaria no 2.488/2011, que instituiu a política nacional de atenção básica (PNAB). São, também, ligadas diretamente à atenção primária, não mais à saúde mental, dispondo do cuidado para a população em situação de rua, com abrangência aos cuidados clínicos e agravos em saúde deste público.

Entretanto, com a execução do Programa + Vida em curso, Recife optou por dar continuidade às equipes de consultório de rua, sendo a única cidade que permanece mantendo os dois formatos de equipe, com as seis equipes do consultório de rua, ao passo que implementou duas equipes de consultório na rua. Essa realidade direciona apenas para o âmbito municipal o financiamento das equipes de redutores(as) de danos, sendo uma importante determinação para a continuidade deste trabalho.

Em 2013, o Programa + Vida foi extinto, logo após a mudança na gestão política municipal do PT para o PSB, com a entrada de Geraldo Júlio. A partir de então, as equipes de consultório de rua permanecem inseridas diretamente nos Caps, vinculando-se à Coordenação de Saúde Mental, Álcool e outras Drogas, sem dispor de coordenação própria.

No lote de desmontes nacionais, marcados expressivamente pelo pós-golpe de 2016, foi sancionada, em 21 de dezembro de 2017, a Portaria no 3.588 (BRASIL, 2017) - ratificada vulgarmente pela Nota Técnica n. 11/ 2019 -, que alterou a política de saúde mental, prevendo alterações nas disposições da Raps. Suas implicações desconsideram os princípios e avanços da reforma psiquiátrica, violando os direitos humanos. Destacamse alterações mais graves, como a manutenção de leitos em manicômios, o firmamento do modelo biomédico, revelado no desfinanciamento dos Caps em virtude do incentivo financeiro às CTs.

Em 2019, o então presidente Jair Bolsonaro (sem partido) instituiu a "nova" política nacional sobre drogas através do Decreto n 9.761/2019, que imprime categoricamente a orientação da abstinência em detrimento da redução de danos. Consequentemente, o direcionamento do texto aponta o fim da redução de danos na política sobre drogas e acentua a participação das comunidades terapêuticas no circuito de tratamento para usuários de álcool e outras drogas, sem qualquer menção aos Centros de Atenção Psicossociais. Juntamente à direção da "nova" política, a Lei no 13.840/ 2019 (BRASIL, 2019) alterou o Sistema Nacional de Políticas Públicas sobre Drogas (Sisnad), com especial dedicação à regulamentação das comunidades terapêuticas e à internação compulsória de usuários de substâncias psicoativas, contrariando as conquistas históricas da reforma psiquiátrica brasileira. 


\section{Os(as) redutores(as) de danos do consultório de rua: desafios, práticas e disputas}

Com a contextualização que marca o fim do Programa + Vida em 2013 e o processo de desmonte na política de drogas, os tópicos apontados a seguir representam a realidade com base no que foi frequentemente apresentado nos conteúdos das entrevistas. Na busca por compreender as mudanças nas ações dessas equipes, essas entrevistas desenrolaram-se numa relação comparativa de como era e como está a prática dos ARDs:

Reunião e formação continuada: durante as entrevistas, todos(as) os(as) entrevistados(as) relataram a interrupção das reuniões semanais de supervisão para o consultório de rua como um processo negativo, pois tratava-se de um espaço que agregava todos(as) os(as) redutores, e que não ocorrem desde 2013:

Nós tínhamos, toda quinta-feira de manhã, reunião com o coordenador de território, e quinzenalmente nós tínhamos espaço de supervisão [...]. Então era um espaço muito rico, onde a gente podia trocar entre as equipes, onde a gente tinha capacitação, onde a gente podia trazer as angústias da gente. Muitos conflitos também com as equipes dos Caps, que eram muito fechadas, que não entendiam a proposta da redução de danos, que achavam que a gente ia sair por aí distribuindo cachimbo, seringa e era 'oba oba'; era um bando de doido, um bando de usuário que tava querendo dar direito para usuários. (ARD. 1).

Isso pra mim foi uma perda! A supervisão do Caps não dá conta dessa supervisão: a supervisão da rua, do território, da saúde mental desse redutor [...]. Acho que é a maior perda, porque a gente perdeu a relação de amizade, de se ver, de conversar, da experiência, de aprender. (ARD. 3).

Três relatos sinalizaram que a interrupção das reuniões foi uma decisão da gestão municipal e que as tentativas de retomadas são falhas. Sem os espaços de reuniões para articulação e construção da atuação prática do consultório de rua, é perceptível um processo de desmobilização coletiva, visto as perdas nas trocas de experiências, na aprendizagem e na comunicação. Isso repercutiu diretamente na produção de processos de trabalho diferentes para cada equipe alocada em cada Caps.

Insumos e infraestrutura: os insumos são uma parte integrante das ações de redução de danos e a falta desses materiais enfraquece as estratégias de cuidado. Três dos oito entrevistados demonstraram insatisfação com os limites institucionais impostos na cidade de Recife, mesmo no período do Programa + Vida, com relação à oferta ampliada de insumos para redução de danos, como cachimbo, seda etc. De outra forma, redutores de quatro das seis equipes relataram a falta de materiais informativos para educação 


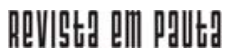

\} ATAQUES À REDUÇÃO - ARAÚJO, E. N. L. \}

DOI: $10.12957 /$ REP.2022.63527

em saúde e orientações para pessoas que buscam acolhimento em algum serviço na rede, anteriormente disponível, como apresenta a fala a seguir:

Carro que não temos, fardamento que não temos, né? Os insumos são os mesmos: camisinha, preservativo masculino e preservativo feminino, água quando tem, e só. Não tem um panfleto indicativo, lúdico, para a gente poder estar ofertando nas ações lá na praça do Sargento, que tem muitos usuários. E a gente não tem material, a gente tira xerox do telefone, faz um quadradinho e tal. Então, assim, de recursos mesmo, de insumos... desde que entrei, que é uma coisa supérflua, a não ser o preservativo masculino e feminino, e água quando tem. Fora isso, mais nada. (ARD. 7).

Nesse contexto, a principal dificuldade relaciona-se à disponibilidade de transporte, para as ações nas ruas, sendo esta uma problemática recorrente nos serviços da Raps. Apenas um redutor de uma equipe referiu não ter problemas de acesso a carro.

Recursos humanos: uma questão relatada por todos os entrevistados, já que desde o concurso e a seleção no início da década não houve nenhuma contratação de novos profissionais.

Eram 70 vagas, das 70 vagas hoje a gente não tem 15 redutores do concurso. Agora, da Santa Casa, do contrato, a gente tem 12, mas na época foram 40. E foram saindo, saindo [...]. E do concurso, a maioria que entrou não se identificou, os que a gente tem hoje ainda lá são os de antes e os que se identificaram. (ARD. 5).

Quando se reduziu esse cuidado do redutor no sentido da rua, a gente ficou muito pouquinho para um mundo de pessoas [...]. Éramos três, a gente colocava a fardinha e ia, mas não tinha uma grande visibilidade porque não era um projeto, de chegar com uma kombi de insumos, com pessoas a mais. A gente foi se tornando formiguinhas. Eu acho que a redução de danos ainda é formiga. (ARD. 6).

Sobre esse esvaziamento, as explicações encontradas por alguns entrevistados atravessam o campo das particularidades, explicadas como "questões pessoais". Outros(as) entrevistados(as) consideram duas motivações maiores: a não identificação de muitos aprovados no concurso com a atuação do agente redutor de danos e a cotidiana desvalorização do trabalho destes profissionais na rede, desde o salário aos desdobramentos do fim do + Vida e desmonte da política de saúde mental. A exemplo da precarização, os(as) ARDs sequer possuem direito à insalubridade. Nessas condições, o número de redutores nas equipes varia de cinco até duas pessoas por equipe.

Redirecionamento do processo de trabalho: vinculados diretamente aos Caps, sem coordenação e gerência própria, e com todas as barreiras apresentadas, os(as) redutores(as) de danos foram impelidos e incorporados no processo de trabalho dos Caps. Algumas equipes não realizam 


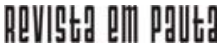

\} ATAQUES À REDUÇÃO - ARAÚJO, E. N. L. \}

DOI: $10.12957 /$ REP.2022.63527

mais ações noturnas, outras possuem redutores(as) atuando nas atividades internas dos Caps, em acolhimentos ou grupos. Dessa forma, é perceptível que os ARDs passaram a ocupar lacunas deixadas pelo desmonte na política de saúde mental, realizando atividades que são dos técnicos de referência dos Caps.

Eu mesmo fico mais interno do que externo. É a realidade, entendeste? Por quê? Porque não tem carro, certo? O Caps tem um déficit de profissionais e aí às vezes a gente tem que fazer grupo, tem que dar suporte, fazer corpo a corpo, fazer acolhimento. Entendeu? Então, assim, perde um pouco o foco do que realmente é a redução de danos dentro do território. Matriciamento com PSF, reunião sistemática com o CRAS, com a justiça, com líder comunitário, entendeste? A gente não está fazendo isso. A gente está com um buraco no território imenso porque a gente não está com esse acesso direto. (ARD. 4).

Das ações e incidência nos territórios: a dinâmica relacional dos territórios produz e é produto de questões antagônicas no campo da totalidade social. Nesses territórios estão as cenas de uso, o conhecimento sobre o fluxo do tráfico e a forma como isso afeta as relações entre as pessoas e as drogas. Seis ARDs sinalizaram a dificuldade de cobertura direta nos territórios, como a fala do ARD4:

Antes a gente conhecia o território como um todo, hoje a gente conhece o território pelas beiradas, feito papa. A gente não tem aquela ação no foco mesmo. Por quê? Porque a gente não tá diretamente dentro do território. A gente vai para o território uma vez perdida, sistematicamente, não é aquela coisa certinha que era antes, que você marcava com um usuário de $8 \mathrm{~h}$ na praça da Mauricéia e ele estava lá, esperando a gente para conversar, para trocar uma ideia, para dizer que aumentou ou diminuiu o uso de drogas, que a redução do crack para a maconha foi legal para vida dele, que começou a tomar água, mudou da lata para cachimbo. Está fumando na seda e não no guardanapo, entendesse? Isso a gente não tem mais. Esse link com o usuário. Esse corpo a corpo com o usuário. A gente perdeu essa essência. (ARD. 4).

A descontinuidade das ações de RD nos territórios caracteriza a fragilidade do vínculo e do cuidado à população usuária, que, muitas vezes, vê nos redutores de danos uma porta de acesso aos serviços de saúde e de outras políticas sociais. É importante afirmar que a ausência rebordosa das equipes nos territórios afeta, principalmente, a população em situação de rua que dialoga diretamente com os redutores em uma perspectiva direta de vínculo e cuidado.

É fato que o desfecho do Programa + Vida e sua valorativa contribuição enquanto implementação da redução de danos no âmbito públicomunicipal não emerge somente de um desacordo programático partidário 


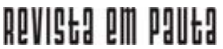

\} ATAQUES À REDUÇÃO - ARAÚJO, E. N. L. \}

DOI: $10.12957 /$ REP.2022.63527

entre o PT e PSB. Trata-se, antes de tudo, de respostas estruturais à crise do social-liberalismo no Brasil, frente à convulsão econômica que se manifesta mundialmente em 2008, mas ganha impulso no país na década seguinte. Nesse enredo, as ações de redução de danos são estruturas frágeis e não hegemônicas, que dispõem basicamente de recursos humanos e tecnologias leves em saúde. É perceptível, no decorrer dos anos, que a implantação, estruturação e ampliação das ações de redução de danos não foram viabilizadas. Ao contrário, o sucateamento do programa se deu por estratégias de reorientação e "ajustes" na gestão do processo de trabalho, já que as entrevistas indicaram um processo silencioso e sutil de desarticulação das ações de redução de danos com a desconfiguração e descontinuidade do processo de trabalho.

Há de se perguntar se essas mudanças do consultório de rua são frutos de uma escolha política diferente do que outrora foi projetado, quando o município resolveu bancar a permanência do consultório de rua, mesmo lançada a portaria que sinaliza a mudança do para o consultório na rua. Entretanto, em uma breve busca nos planos municipais de 2014-2017 e 2018-2021, as duas equipes de consultório na rua, implementadas antes de 2014, também permaneceram nos dois planos, sem perspectiva de ampliação ou propostas estratégicas de ações.

No contexto conservador e repressivo que delineia a questão das drogas no Brasil, a contrarreforma no SUS e seus desdobramentos no fazer estratégico da redução de danos dificultam a realização de estratégias contrahegemônicas ao proibicionismo e ao paradigma da abstinência. Consoante a desvalorização das ações de redução de danos na cidade, as articulações político-partidárias - de base fundamentalista e neopentecostais - no município em favor do mercado das comunidades terapêuticas (CTs) passaram a ocupar cada vez mais espaço no tratamento de pessoas usuárias de álcool e outras drogas, com a notória participação de parlamentares representantes de clãs familiares que dominam esse mercado.

Não obstante, "quanto mais o SUS é precarizado, mais cresce o mercado de serviços privados" (SOARES, 2020, p. 71), neste caso, visando à disputa pelo fundo público da política sobre drogas e seu financiamento no âmbito do SUS. A exemplo disso, em 2015, a prefeitura do Recife lançou edital para o financiamento de 150 vagas para adolescentes e adultos em comunidades terapêuticas, sob custeio público de $\mathrm{R} \$ 40,00$ cada, ao dia. Nos anos recentes, alinhada ao cenário nacional e principalmente aos anseios da bancada fundamentalista, a prefeitura do Recife tem se envolvido em diversas articulações com o nicho de CTs, a exemplo do Programa Rede Viver e o Programa Acolhe Vida ${ }^{3}$.

\footnotetext{
${ }^{3}$ Na última eleição municipal de 2020, a pauta da atenção aos usuários de drogas foi bastante disputada nos debates das duas principais candidaturas à prefeitura, ambas acenando para a continuidade das articulações com as CTs. Além disso, vereadores(as) como Michelle Collins, Luís Eustáquio, Jr. Tércio e Fred Ferreira, representantes, empresários e/ou porta-vozes das CTs, alçaram o terreno da ala conservadora no espaço parlamentar.
} 


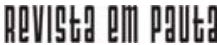

\} ATAQUES À REDUÇÃO - ARAÚJO, E. N. L. \}

DOI: $10.12957 /$ REP.2022.63527

Essa contextura afeta diretamente as agendas político-sociais locais. O bloco político - do PSB - que estimula a redução de danos com o Programa Atitude, ainda em 2011, no governo estadual, é o mesmo dos anos posteriores na esfera municipal que alça espaço para o modelo das CTs. Essas contradições inerentes à sociabilidade capitalista são expressas pelas articulações parlamentares em um contexto de crise social e política, no qual o conservadorismo assume tarefas essenciais na agenda neoliberal brasileira.

\section{Considerações finais}

A implementação de ações de redução de danos através dos(as) ARDs em Recife, por constantemente coabitar disputas internas com o paradigma proibicionista da abstinência, mesmo numa gestão progressista, não conseguiu atravessar limites necessários para consolidar intervenções antiproibicionista, ainda que sua continuidade mereça destaque nacional pela construção de caminhos preciosos à prática da redução de danos.

Apresentado em seus pormenores, o desmonte das ações de redução de danos em Recife articula aspectos dos interesses econômicos, políticos e ideológicos locais, apresentados pela "vontade política" da gestão municipal, ao contexto brasileiro de ajustes na agenda neoliberal. A consolidação expressiva dos interesses econômicos de setores fundamentalistas nos espaços parlamentares, que engendram disputas facilmente cedidas pelas relações de coalizões dos espaços legislativos, são provas de como o ideário conservador é uma tendência conjuntural do atual momento de crise do capital na realidade brasileira.

A racionalidade hegemônica submete a existência do SUS ao projeto neoliberal de contrarreforma (SOARES, 2020). A essa tendência, é perceptível como as mudanças impostas para as equipes do consultório de rua significaram o processo de desmonte incorporando as premissas dessa agenda: ao desmobilizar a articulação política e clínica desses profissionais; ao desconfigurar o processo de trabalho; ao impelir o deslocamento da atuação desses profissionais e ao promover a desarticulação da rede de cuidado a pessoas que fazem uso de substâncias, mediando aspectos que ora indicam a flexibilização das condições de trabalho dos(as) agentes redutores(as) de danos para racionalização do processo de trabalho, ora conformam a possibilidade de extinção total das ações em detrimento de um outro modelo de atenção. Apesar dessa realidade e das fragilidades coletivas na organização política, é perceptível que cotidianamente esses profissionais reinventam o processo de trabalho na tentativa de dar conta das ações de redução de danos, mesmo que às vezes incorporados ao trabalho interno nos Caps.

Nessa empreitada, Recife consolida, no âmbito público-privado, as relações do campo fundamentalista, expressas duplamente nos espaços 


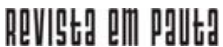

\} ATAQUES À REDUÇÃO - ARAÚJO, E. N. L. \}

DOI: $10.12957 /$ REP.2022.63527

parlamentares e nos empreendimentos que lucram com as comunidades terapêuticas, tendência que dialoga com o cenário nacional. Essas articulações de fundamento econômico e o direcionamento de recursos públicos para tratamentos em CTs - à base de orações, violências, trabalhos não pagos e outras práticas manicomiais - promovem o ideário proibicionista e a moral cristão da abstinência e culpabilização desses indivíduos. Indivíduos esses que, na maioria das vezes, estão imersos em problemáticas sociais que vão muito além do uso de drogas e são constantemente enfraquecidos pelo acirramento exponencial das expressões da questão social.

É possível imprimir as funções desses espaços tais como as funções das prisões, adaptando as considerações de Angela Davis (2018, p. 39): "Pode-se dizer que, de várias maneiras, a prisão atua como uma instituição que consolida a inabilidade e a recusa do Estado em enfrentar os problemas sociais mais prementes da atualidade".

Por fim, a defesa da RD está contida na defesa dos direitos sociais. Nesse sentido, as ações dos(as) ARDs foram e continuam sendo responsáveis por um processo humanizado e crítico de atenção à saúde mental, e precisam ser reivindicadas como práticas necessárias nos espaços da rede junto a todos(as) os(as) profissionais de saúde, e presentes nos territórios. Este é um caminho de cuidado que defronta cotidianamente a lógica de uma sociedade classista, manicomial, proibicionista e racista! 


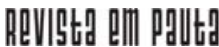

\} ATAQUES À REDUÇÃO - ARAÚJO, E. N. L. \}

DOI: $10.12957 /$ REP.2022.63527

\section{Referências}

BARROCO, M. L. S. Não passarão! Ofensiva neoconservadora e serviço social. Serviço Social e Sociedade, 2015.

BRASIL. Portaria n. 3.088, de 23 de dezembro de 2011 (republicada 2013). Institui a Rede de Atenção Psicossocial para pessoas com sofrimento ou transtorno mental e com necessidades decorrentes do uso de crack, álcool e outras drogas, no âmbito do Sistema Único de Saúde (SUS). Brasília, Diário Oficial da União, 23 dez. 2011.

BRASIL. Portaria n. 3.588, de 21 de dezembro de 2017. Altera as Portarias de Consolidação n. 3 e n. 6, de 28 de setembro de 2017, para dispor sobre a Rede de Atenção Psicossocial, e dá outras providências. Brasília, Diário Oficial da União, 2017.

BRASIL. Lei n. 13.840, de 5 de maio de 2019. Dispõe sobre o Sistema Nacional de Políticas Públicas sobre Drogas e as condições de atenção aos usuários ou dependentes de drogas e para tratar do financiamento das políticas sobre drogas. Brasília, Diário Oficial da União, 2019.

BRITES, C. M. Ética e uso de drogas: uma contribuição da ontologia social para o campo da saúde pública e da redução de danos. Tese (Doutorado em Serviço Social) - Programa de Estudos Pós-Graduados em Serviço Social, Pontifícia Universidade Católica de São Paulo, São Paulo, 2006.

BRITES, C. M. Psicoativos (drogas) e Serviço Social: uma crítica ao proibicionismo. São Paulo: Editora Cortez, 2017.

CARNEIRO, H. Drogas: a história do proibicionismo. São Paulo: Editora Autonomia Literária, 2018.

DAVIS, A. A liberdade é uma luta constante. São Paulo: Boitempo Editorial, 2018.

FONSECA, E. M. Políticas de redução de danos ao uso de drogas: o contexto internacional e uma análise preliminar dos programas brasileiros. Tese (Doutorado em Saúde Pública) - Escola Nacional de Saúde Pública Sergio Arouca, Fundação Oswaldo Cruz, Rio de Janeiro, 2005.

MARX, K. O capital. Livro I. São Paulo: Boitempo, 2011.

MEDEIROS, P. F. P. et al. Um estudo sobre a avaliabilidade do Programa + Vida: política de redução de danos em álcool, fumo e outras drogas do município de Recife, Brasil. Revista Brasileira de Saúde Matern. Infantil, Recife, v. 10, n. 1, nov., 2010. Disponível em: https://www.scielo.br/j/rbsmi/ a/6Kd3DHWCkdsX8gyqP4JQ5hH/?format=pdf\&lang=pt. Acesso em: 20 out. 2020 . 


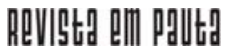

\} ATAQUES À REDUÇÃO - ARAÚJO, E. N. L. \}

DOI: $10.12957 /$ REP.2022.63527

MELO, T. A. G. Memórias sobre a política de saúde mental em Recife: entre passos, descompasso e controvérsias. Tese (Doutorado em Psicologia) - Programa de Pós-Graduação em Psicologia, Universidade Federal de Pernambuco, Recife, 2017.

MORAES, M. M. O modelo de atenção à saúde para tratamento de problemas decorrentes do uso de drogas: percepções de usuários, acompanhantes e profissionais. Dissertação (Mestrado em Saúde Pública) CPqAM, Fiocruz/PE, Recife, 2005.

PASSOS, E. H.; SOUZA, T. P. Redução de danos e saúde pública: construções alternativas à política global de "guerra às drogas". Psicologia e Sociedade, v. 23, n. 1, 2011. Disponível em: https://www.scielo.br/j/psoc/ a/zMk4Dq4gQ4XhH4dQgzScQRm/abstract/?lang=pt. Acesso em: 20 out. 2020.

PLENA, M. G. et al. Consultório de rua do SUS. Material de trabalho para a II Oficina Nacional de Consultórios de Rua do SUS. Brasília: Ministério da Saúde, 2010.

RAMEH-DE-ALBUQUERQUE, R. C. et al. Do descaso a um novo olhar: a construção da Política Nacional de Atenção Integral aos Usuários de Álcool e Outras Drogas como conquista da reforma psiquiátrica brasileira. O caso de Recife (PE). Psicologia em Pesquisa, v. 11, n. 1, 2017. Disponível em: http://pepsic.bvsalud.org/scielo.php?script=sci_abstract\&pid=S198212472017000100010. Acesso em: 20 out. 2020.

SOARES, R. C. Contrarreforma no SUS e o Serviço Social. Recife: Ed. UFPE, 2020.

SOUZA, D. O. A questão do "consumo de drogas": contribuições para o debate. Serviço Social E Saúde, v. 11, n. 2, p. 269-286, 2012.

WACQUANT, L. As prisões da miséria. Rio de Janeiro: Jorge Zahar, 2001.

WEST, R. S. Política de drogas e redução de danos: um estudo sobre o Programa Atitude em Pernambuco. Dissertação (Mestrado em Ciências Políticas) - Programa de Pós-Graduação em Ciências Políticas, Universidade Federal de Pernambuco, Recife, 2016.

DOI: $10.12957 /$ rep.2022.63527

Recebido em 05 de julho de 2021. Aprovado para publicação em 15 de outubro de 2021.

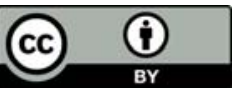

A Revista Em Pauta: Teoria Social e Realidade Contemporânea está licenciada com uma Licença Creative Commons Atribuição 4.0 Internacional. 